\title{
Experiences in the prevention, control and elimination of iodine deficiency disorders: a regional perspective
}

\author{
F. Azizi' and L. Mehran²
}

\begin{abstract}
SUMMARY Before 1987, iodine deficiency was not considered an issue of major importance in the countries of the Eastern Mediterranean Region (EMR). Progress began with a systematic national study of goitre and other iodine deficiency disorders (IDD) in the Islamic Republic of Iran in 1983. Following a major review of the prevalence of IDD in member states, Guidelines for national programmes for the control of iodine deficiency disorders in the EMR were published by the World Health Organization (WHO) in 1988. This paper discusses progress towards elimination of iodine deficiency by reviewing the status of IDD in the countries of EMR and programmes for prevention and control of IDD with particular reference to the Islamic Republic of Iran, the first country to be declared IDD-free by WHO.
\end{abstract}

\section{Introduction}

Although a high prevalence of goitre and severe iodine deficiency in the Chitral and Gilgit regions of Pakistan was first reported as far back as 1908 [1], prior to 1987 iodine deficiency was not considered an issue of major importance in the countries of the Eastern Mediterranean Region (EMR). Despite the high rates in many areas of many countries of the Region (for example, Mosul province in Iraq, Shahryar in the Islamic Republic of Iran, and in most regions of Lebanon), goitre was regarded as being strictly restricted to certain geographical areas and thus not considered as an important public health problem $[2,3]$. Therefore, surveys in EMR countries had been limited to one or two endemic areas. This changed in 1983, when the Islamic Republic of Iran began to systematically study the prevalence of goitre and other iodine deficiency disorders and in 1989 conducted a national survey of iodine deficiency disor- ders (IDD), which revealed hyper-endemic and endemic goitre in all provinces of that country [4].

\section{Progress in monitoring and control of IDD}

A major landmark in IDD control in the EMR was a review of the prevalence and control measures of IDD in EMR member states in 1987 [2]. For the first time, member states were alerted to the fact that, in a number of countries of this Region, IDD was a major public health problem meriting serious consideration and urgent action. Table 1 summarizes the major activities related to IDD in the last 15 years.

In order to respond to the growing interest of the member states, the EMR Office (EMRO) of the World Health Organization (WHO) convened an inter-country consultation of experts in December 1987 to collect more information, exchange ex-

${ }^{1}$ Director, ${ }^{2}$ Endocrine Research Centre, Shaheed Beheshti University of Medical Sciences, Tehran, Islamic Republic of Iran.

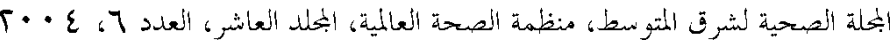




\begin{tabular}{ll}
\hline $\begin{array}{l}\text { Table 1 Major iodine deficiency disorder (IDD) activities in the Eastern } \\
\text { Mediterranean Region (EMR) since 1987 }\end{array}$ \\
\hline Year & \multicolumn{1}{c}{ Activity } \\
\hline 1987 & Review of IDD in EMR member states \\
1987 & Inter-country consultation about IDD convened by WHO-EMRO \\
1988 & Publication of EMRO guidelines for national IDD control programmes \\
1989 & First Regional IDD survey and start of IDD control programme \\
1990 & in Islamic Republic of Iran. \\
1990 & Inter-country workshop in IDD (Tehran) \\
1992 & Discussion of IDD at 37th session of WHO-EMRO Regional meeting \\
1994 & Training workshop for laboratory staff (Damascus) \\
1995 & UNICEF Middle East North Africa Regional IDD workshop (Tehran) \\
1996 & First Regional meeting of salt producers (Jordan) \\
1999 & lodine sufficiency achieved in Islamic Republic of Iran \\
2000 & Symposium/workshop on assessment and monitoring of IDD (Tehran) \\
2000 & Regional meeting for promotion of iodized salt (Dubai) \\
& Islamic Republic of Iran and Tunisia declared IDD-free countries. \\
$2001 \& 2002$ & Salt iodization started in 17 countries. Universal salt iodization \\
& achieved in 6 countries \\
& First and second IDD Regional training course on monitoring and \\
& evaluation of IDD elimination (Tehran)
\end{tabular}

periences and develop guidelines that would assist countries to define the problem and mount national control programmes. These guidelines were published (in Arabic and English) in 1988 as EMRO Technical Publication No. 12, entitled Guidelines for a national programme for the control of iodine deficiency disorders in the EMR.

In 1990, an inter-country workshop on IDD was held in Tehran to exchange experiences and to develop approaches. Subsequently, a technical paper was presented to the 37th session of the WHO Regional Committee for the Eastern Mediterranean, alerting the ministers of health of all countries in the Region to the devastating effect of IDD on brain development and cognitive function. Since then, WHO, often jointly with UNICEF and the International Council for the Control of Iodine Deficiency Disorders (ICCIDD), has made great efforts to support countries in their efforts to deal with this very important deficiency.

A number of important workshops and training courses have been held. A WHO tri-Regional travelling seminar was organized with EMRO and the South-East Asia and Western Pacific Region Offices in India and Nepal in 1991 to observe salt and oil iodization in practice. The first meeting on universal salt iodization for salt producers in the EMR Region was held in Jordan in 1995 and a number of technical consultancies were conducted. Among these, UNICEF held a Regional IDD workshop in 
1994 in Tehran and WHO held a symposium workshop on assessment and monitoring of IDD in countries of EMR in 1999, also in Tehran [5].

In 1988, the Islamic Republic of Iran carried out the first national IDD survey in the Region, which revealed a high prevalence of IDD [4]. By 1999, Egypt, Jordan, Lebanon, Morocco, Oman and the Syrian Arab Republic had also carried out surveys. The Islamic Republic of Iran and the Syrian Arab Republic were the first countries in the Region to start iodizing salt. The first Regional meeting of salt producers in the EMR, held in 1995, led to the establishment of a Regional association of iodized salt producers.

By late 1998, 13 countries, and by 2004, 16 countries, had initiated salt-iodization programmes and 6 countries had reached the goal of universal salt iodization by demonstrating that at least $90 \%$ of households consume adequately iodized salt (Table 2).

The Islamic Republic of Iran was the first country in the Region to become iodine sufficient by showing that more than $95 \%$ of households consumed adequately

Table 2 Progress in control of iodine deficiency disorders (IDD) in countries of the Eastern Mediterranean Region in the year 2004 (adapted from WHO-EMR report [8])

\begin{tabular}{lc}
\hline IDD status & No. of countries \\
\hline IDD a problem & 18 \\
Legislation in place & 17 \\
Salt iodization begun & 16 \\
Universal salt iodization achieved & 6 \\
IDD under control achieved & 2 \\
\hline
\end{tabular}

iodized salt and the median urinary iodine level was above $100 \mu \mathrm{g} / \mathrm{L}$ in each of the 26 provinces [6]. More recently, Tunisia also achieved satisfactory iodine status and both countries were accorded IDD-free status by WHO-EMRO in the year 2000 [6]. In 2001, the Endocrine Research Centre and the Ministry of Health of the Islamic Republic of Iran were appointed by WHOEMRO to hold an annual training course on monitoring and evaluation of IDD elimination programmes. The first 2 courses were offered in 2001 and 2002 with the participation of 12 and 21 countries of the Region and countries of Central Asia and Eastern Europe respectively.

\section{Status of IDD in the Region}

By 2004, the status of IDD in the EMR countries was as follows:

- IDD under control: Islamic Republic of Iran and Tunisia;

- Mild IDD: Jordan, Lebanon, Libyan Arab Jamahiriya, Egypt, Palestine, Oman, Bahrain, Qatar, Syrian Arab Republic, United Arab Emirates, Kuwait and Yemen;

- Moderate IDD: Morocco, Sudan and Saudi Arabia;

- Severe IDD: Iraq, Afghanistan and Pakistan.

Table 3 shows the most recent information about the IDD status of the countries of EMR. In 8 of 17 countries the median urinary iodine level was $\geq 10 \mu \mathrm{g} / \mathrm{dL}$ and in 11 of 17 countries the proportion of households consuming iodized salt was $>50 \%$. Figures 1 and 2 show the distribution of household iodized salt consumption and median urinary iodine levels in the countries of EMR.

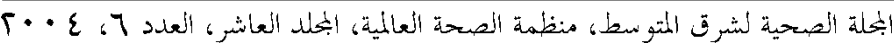




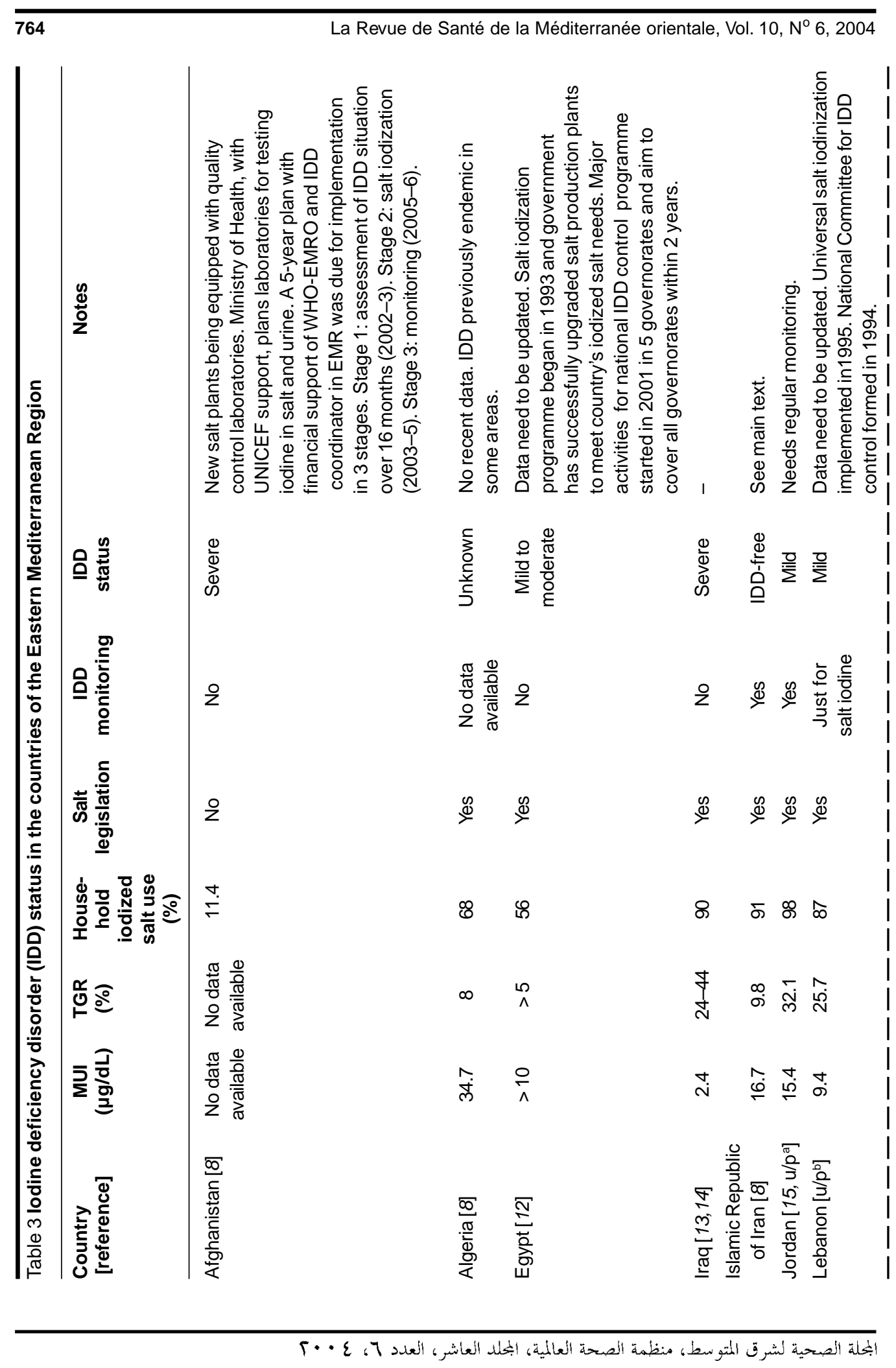


\begin{tabular}{ll}
\hline Eastern Mediterranean Health Journal, Vol. 10, No. 6, 2004 & 765
\end{tabular}

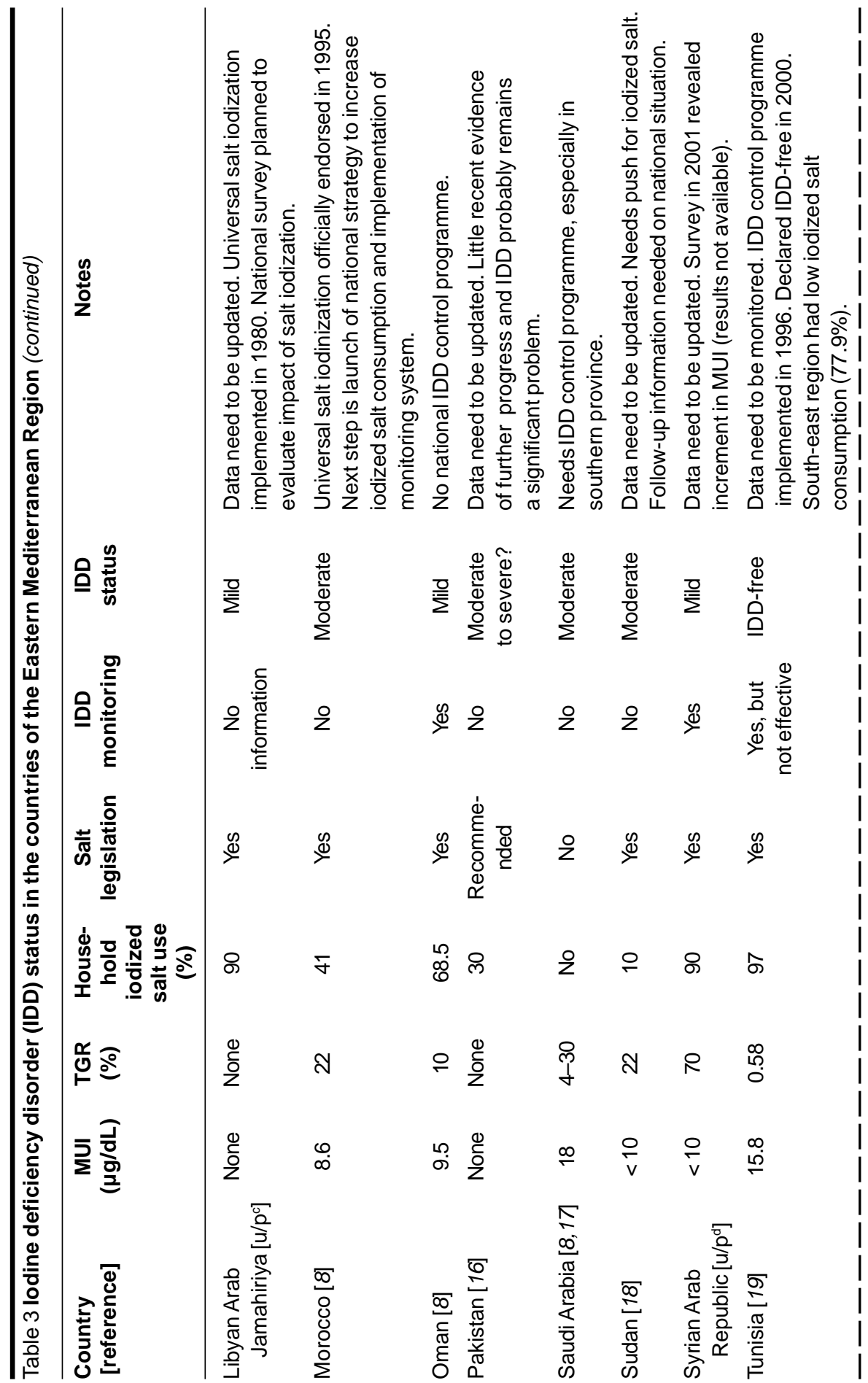

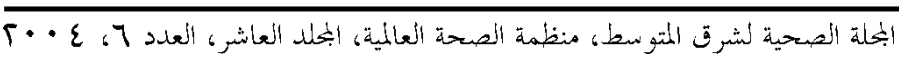




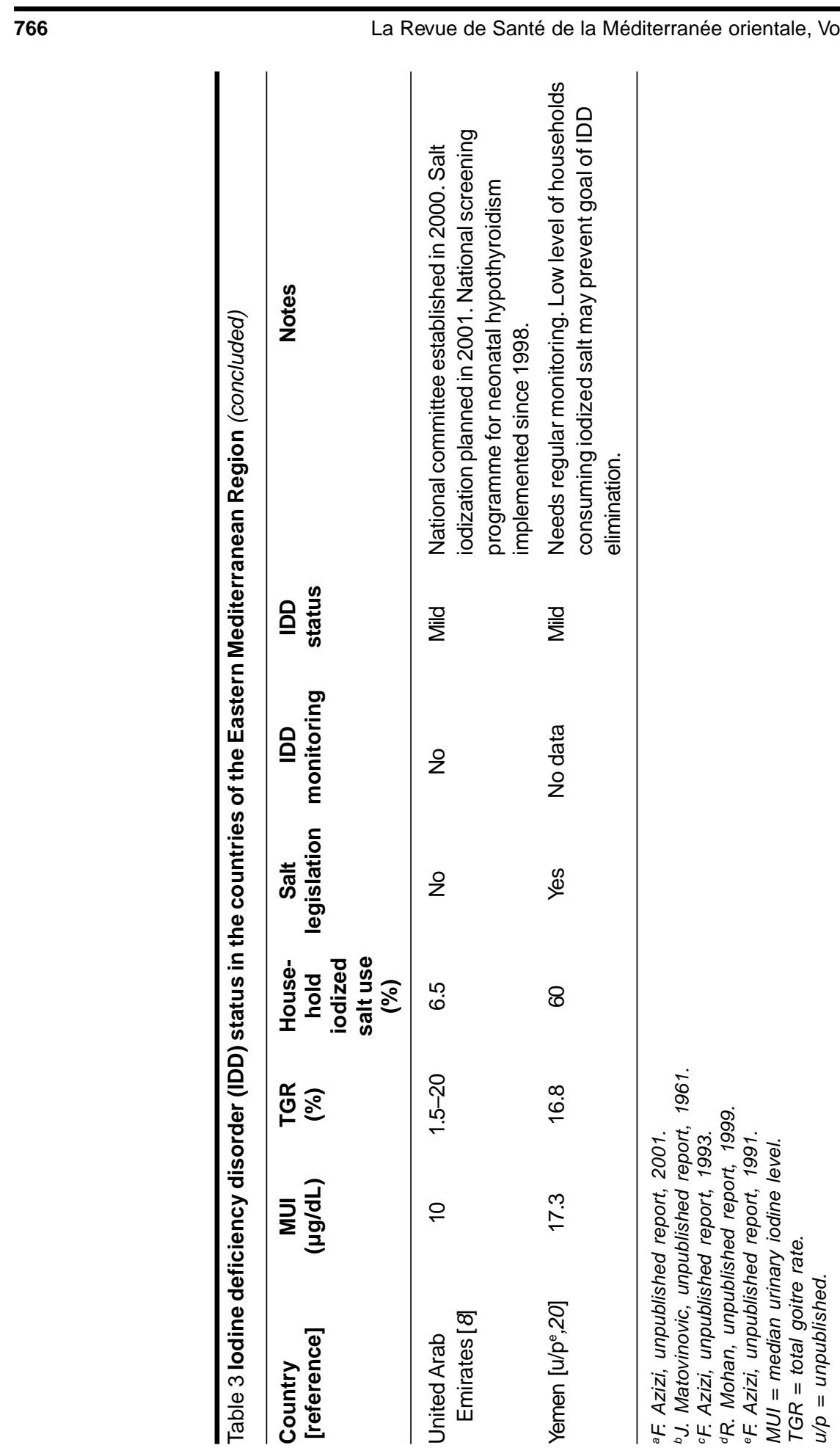

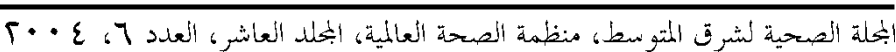



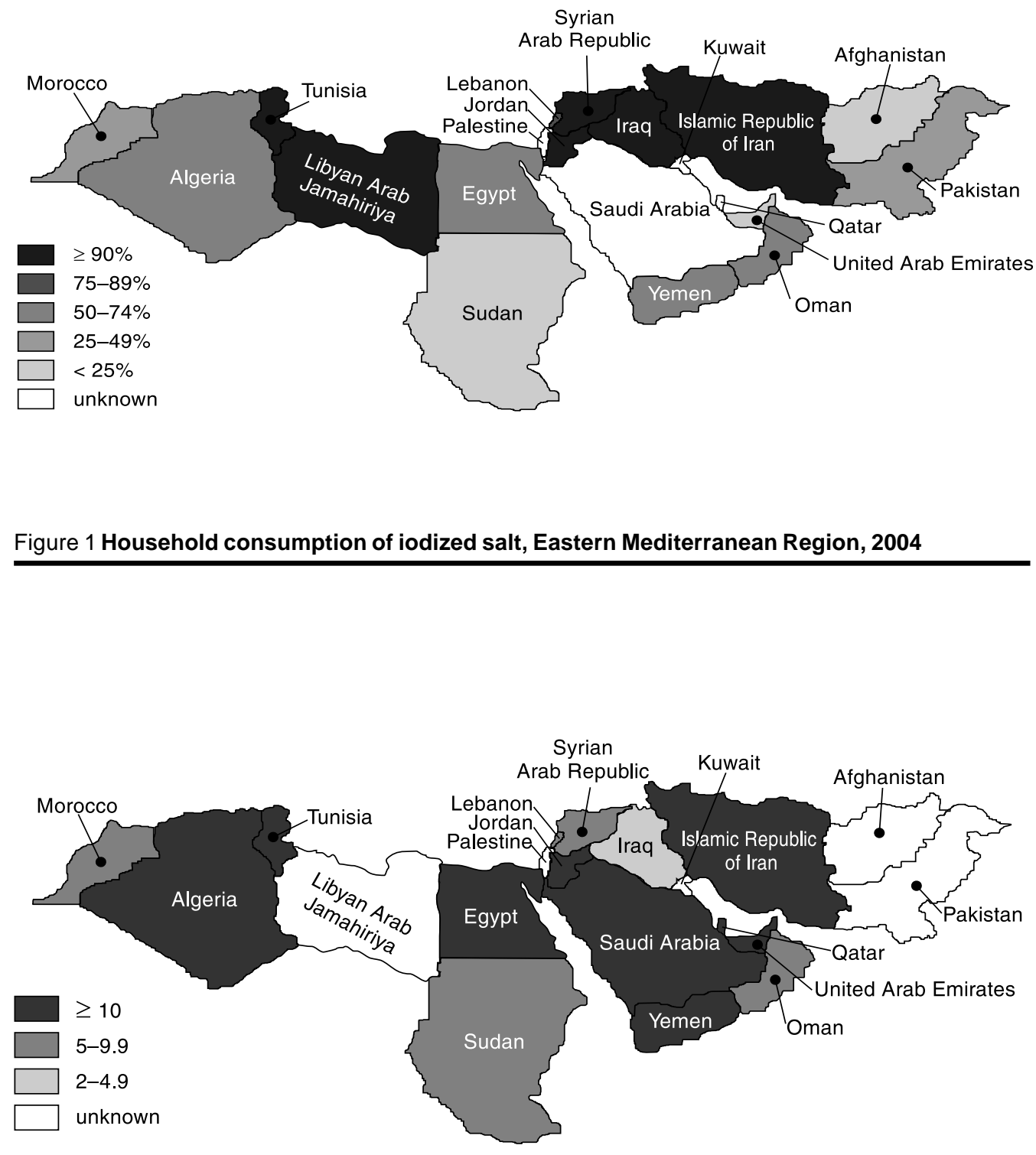

Figure 2 Median urinary iodine levels ( $\mu \mathrm{g} / \mathrm{dL}$ ), Eastern Mediterranean Region, 2004

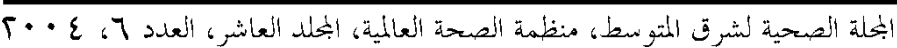




\section{The Iranian experience}

The Islamic Republic of Iran conducts an optimal programme for control of IDD. A sustainable and well-managed iodization programme is functioning in the country with the programmatic indicators set by WHO/UNICEF/ICCIDD [7,8].

The programme began in 1988, when reports of hyper-endemic and endemic areas of goitre in different parts of the Islamic Republic of Iran $[9,10]$ prompted the Ministry of Health and Medical Education to form the Iranian National Committee for Control of IDD (INCCI). A nationwide survey, performed under the supervision of INCCI, showed that goitre was endemic in all cities and hyper-endemic in the capital cities of 5 provinces [4]. Median urinary iodine excretion was $<100 \mu \mathrm{g} / \mathrm{L}$ in all localities and $<20 \mu \mathrm{g} / \mathrm{L}$ in many localities examined $[4,9,10]$.

The INCCI prepared a national plan, which detailed objectives and strategies for IDD control. Iodization of household salt supplies began in 1990. Although the production, distribution and consumption of iodized salt increased gradually, a nationwide survey in 1993 showed that less than $50 \%$ of the households were using iodized salt [11]. INCCI announced universal salt iodization and all salt factories were obliged by law to produce only iodized salt for household use. National surveys in 1994, 1996 and 1998 showed that more than 95\% of Iranian households were consuming iodized salt [11].

Figure 3 shows the major reduction in the prevalence of goitre from the first Iranian national survey in 1989 to monitoring surveys in the years 1996 and $2001[4,7]$. In 1996, in the framework of the IDD monitoring programme, the second national survey was conducted 2 years after the implementation of the new law for manda-

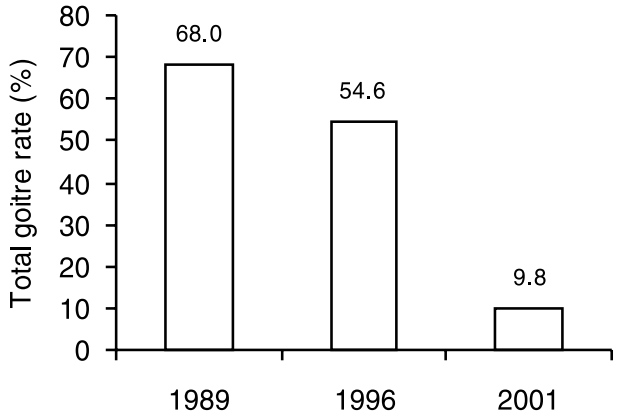

Figure 3 Total goitre rate in 3 national surveys (1989, 1996 and 2001) in the Islamic Republic of Iran $[4,11]$

tory salt iodization [11]. The total goitre rate was $54.6 \%$ and it was evident that the prevalence of goitre was still high in many provinces. The study was performed when the majority of people had used iodized salt for only for 2 years and the majority of 8to 10 -year-old children had, at the time, passed most of their life without adequate iodine supplementation. It was therefore too early to expect that the consumption of iodine should result in a reduction of goitre prevalence. The latest national IDD survey in 2001-02 showed a significant reduction in total goitre rate to $9.8 \%$. The prevalence of goitre grade 2 in 22 provinces was lower than $5 \%$ and in the other provinces the goitre rate did not exceed $10 \%$.

The most sensitive method for the monitoring and evaluation of an IDD control programme is the determination of urinary iodine excretion. The 1996 Iranian national survey showed that the median urinary iodine excretion in schoolchildren $(20.5 \mu \mathrm{g} / \mathrm{dL})$ was at the top of the optimal range $(10$ to $20 \mu \mathrm{g} / \mathrm{dL})$ recommended by WHO/UNICEF/ICCIDD [7,8] and 85.1\% of children had urinary iodine $\geq 10 \mu \mathrm{g} / \mathrm{dL}$. By 2001, median urinary iodine was 16.7 
$\mu \mathrm{g} / \mathrm{dL}$ and only $5.8 \%$ of the study population had urinary iodine $<5 \mu \mathrm{g} / \mathrm{dL}$ which, based on international standards, is favourable.

According to these criteria, the Islamic Republic of Iran appears to have reached a sustainable IDD control programme since 1996, an achievement that was recognized by WHO-EMRO in the year 2000 [6]. Monitoring of the IDD control programme is planned every 5 years to evaluate the sustainability of the programme.

The lessons from the Iranian experience are that implementation of an adequate and sustainable programme of IDD control requires many effective programmatic steps, in particular integration of IDD control into the health network and mandatory iodization of household salt.

\section{References}

1. McCarrison R. Observations on endemic cretinism in the Chitral and Gilgit valleys. Lancet, 1908, 2:1275-80.

2. Baghchi $\mathrm{K}$, Rejeb $\mathrm{H}$. lodine deficiency disorders in the Eastern Mediterranean. Eastern Mediterranean Region health services journal, 1987, 3:22-6.

3. Benmiloud M. lodine deficiency disorders in the Middle East. In: The prevention and control of iodine deficiency disorders. Hetzel BS, Dunn JT, Stanbury JB, eds. Amsterdam, Elsevier, 1987: 265-71.

4. Azizi F et al. Current status of iodine deficiency disorders in the Islamic Republic of Iran. Eastern Mediterranean Region health services journal, 1990, 8:23-7.

5. Assessment and monitoring of iodine deficiency disorders in countries of the Eastern Mediterranean Region. Report of a symposium-workshop, Tehran, Islamic Republic of Iran, 9-11 September 1999.

6. Regional meeting for the promotion of iodized salt in the Eastern Mediterranean, Middle East and North Africa Region. Dubai, United Arab Emirates, 10-12 April, 2000.

7. Assessment of the iodine deficiency disorders and monitoring their elimination. A guide for programme managers, 2nd ed. Geneva, World Health Organization, 2001 (WHO/NHD/01.1).

8. Azizi F. Assessment, monitoring and evaluation of iodine deficiency disorders in the Middle East and Eastern Mediterranean Region. Tehran, Sara Publications, 2002.

9. Azizi $\mathrm{F}$ et al. Impairment of neuromotor and cognitive development in iodine deficient school children with normal physical growth. Acta endocrinologica, 1993, 129:501-4.

10. Azizi $F$ et al. Physical, neuromotor and intellectual impairment in non-cretinous school children with iodine deficiency. International journal for vitamin and nutrition research, 1995, 65:199-205.

11. Azizi F et al. Sustainable control of iodine deficiency in Iran: beneficial results of the implementation of the mandatory law on salt iodization. Journal of endocrinological investigation, 2002, 25:409-13.

12. Cable Y. Goiter and iodine deficiency in Egyptian oases. American journal of clinical nutrition, 1968, 21:4.

13. Coughey JE, Follis RH Jr. Endemic goitre and iodine malnutrition in Iraq. Lancet, 1965, 14:1032-4.

14. Demarchi M. Prevalence and etiology of goiter in Iraq. American journal of clinical nutrition, 1969, 22:12-6.

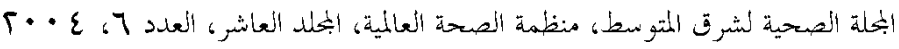


15. Kharabsheh $S$ et al. Goiter prevalence and urinary iodine excretion in schoolchildren of Jordan. International journal for vitamin and nutrition research, 2004, 4:301-4.

16. Siraj-UI-Haq M. Current status of endemic goiter and control measures in Pakistan. In: Dunn JT et al., eds. Towards the eradication of endemic goiter, cretinism and iodine deficiency. Washington DC, WHO Pan American Health Organization, 1986 (PAHO Scientific Publication No. 502).

17. Al-Nuaim AR et al. lodine deficiency in Saudi Arabia. Annals of Saudi medicine, 1997, 17(3):293-7.
18. Eltom $\mathrm{M}$ et al. Endemic goitre in the Darfur region (Sudan). Epidemiology and aetiology. Acta medica scandinavica, 1984, 215:467-75.

19. Hamza M, Boukhris R, Ben Ayed H. Epidemiology of simple goiter. Paper presented at III ème Congrès Médical Maghrébin, Tunis, 14-16 May, 1973.

20. Zein AZ et al. The epidemiology of iodine deficiency disorders (IDD) in Yemen. Public health nutrition, 2000, 3:245-52.

\section{Some facts on iodine deficiency}

- lodine deficiency disorders (IDD) affect over 740 million people, $13 \%$ of the world's population, and $30 \%$ of the remainder are at risk.

- IDD preys upon poor, pregnant women and preschool children, posing serious public health problems in 130 developing countries.

- lodine-deficient people may forfeit 15 IQ points.

- Mearly 50 million people suffer from some degree of IDD-related brain damage.

- We have the means to prevent it - small quantities of iodine which can be delivered in a simple, universally effective and in credibly cheap way - IODIZED SALT.

Further information about IDD and its prevention can be found at: http://www.who.int/nut/idd.htm 